\title{
CONF-950704-14
}

The submitted manueript has been authored

by a contractor of the U.S. Govermment under

contract No. DE-AC05-840R21400.

Accordingly, the U.S. Govermment retains

nosercluaive royalty-free licence to prblish or

reproduce the published form of this

contribution, or allow others to do 10 , for U.S.

$6,0,1 / 20$

DEC 081995

Government purposes."

OS.TI

\section{A Quantitative Study of the Carbon Impurity \\ Production Mechanisms from an Inertial Limiter in \\ Tora Supra as Determined by Visible Spectroscopy*}

by

S. J. Tobin, T. Kammash

The University of Michigan

Nuclear Engineering

Ann Arbor, Michigan USA

J. T. Hogan, R. C. Isler, C. C. Klepper

Oak Ridge National Laboratory

Oak Ridge, Tennessee USA

C. DeMichelis, D. Guilhem, R. Guirlet, W. R. Hess, A. I. Ledyankin, P. Monier-Garbet

Centre d'Etudes de Cadarache

Association EURATOM-CEA

sur la Fusion, France

for

22nd European Physical Society Conference

Controlled Fusion and Plasma Physics

Bournemouth, United Kingdom

*Research sponsored by the U.S. Department of Energy, Office of Fusion Energy, under contract DE-AC05-840R21400 with Lockheed Martin Energy Systems.

DISTRIBUTION OF THS DOCUNENT IS UNLMITED ${ }^{\prime} W$ 


\title{
A Quantitative Study of the Carbon Impurity Production Mechanisms from an Inertial Limiter in Tora Supra as Determined by Visible Spectroscopy
}

\author{
S.J. Tobin $\AA^{*} \kappa$, J.T. Hogan*, C. DeMichelis\&, D. Guilhem ${ }^{\&}$, R.Guirlet\&, W.R. Hess\&, \\ R.C. Isler*, T. Kammash ${ }^{\kappa}$, C.C. Klepper*, A.I. Ledyankin\&, P. Monier-Garbet\& \\ \&Assoc. EURATOM- CEA, DRFC/SPPF, Centre d'Etudes de Cadarache \\ F-13108 Saint Paul-lez-Durance, France \\ *Fusion Energy Division, Oak Ridge National Laboratory \\ Oak Ridge, TN 37831-8072 \\ אThe University of Michigan, Nuclear Engineering \\ Ann Arbor, MI 48109-2104
}

1. Introduction. In a steady-state tokamak, impurity production and transport from plasma facing components will have to be controlled. Recent results from several divertor tokamaks (JT-60U [1], JET [2] and ASDEX-UG [3]) suggest the importance of chemical sputtering as an impurity production mechanism. However, since impurity production is minimized in high recycling divertor configurations, the quantitative characterization of impurity generation is more difficult than in the high heat flux environment of a limiter configuration. Such an experiment was carried out on Tore Supra to examine the absolute carbon flux from the inertially-cooled outboard limiter. Previous Tore Supra experimental and modelling results (BBQ) ([4] and [5]) have shown that chemical sputtering and radiation enhanced sublimation (RES) play a significant role in the total carbon erosion for certain regions of this limiter. Recently, CD molecular spectra, a signature of chemical sputtering, have also been observed. This work describes the observed temperature dependence of the methane and carbon flux.

2. Experimental setup and plasma conditions. The principal diagnostic was a visible spectrometer with an Optical Multichannel Analyzer (OMA) detector. Light emitted by low ionization states near the limiter surface was guided by a mirror to a series of lenses followed by fiber optic cables, each cable imaging a different $2 \mathrm{~cm}^{2}$ region of the limiter. Absolute intensity calibrations of the entire system, performed in the torus before and after an experimental campaign, have shown that the mirror and sapphire window transmission were severely degraded by plasma exposure, thus invalidating the absolute calibrations. However, the relative change in the calibration as a function of wavelengths was understood. To take advantage of this knowledge, it was concluded that a self-consistent absolute calibration could be approximated if the calibration factor was known at one wavelength. It was decided to obtain the calibration factor at $4300 \AA$ by assuming a reasonable methane yield value from published data.

$$
\text { Methane Yield }=\Gamma_{\text {paricle }}^{C D} / \Gamma_{\text {particle }}^{D^{+}}=4 \pi * S / X B\left(T_{e}\right) * \text { brightness }(C D) / n \sqrt{k T_{e} / m_{i}}
$$

The methane yield is a function of three parameters: the electron temperature $\left(\mathrm{T}_{\mathrm{e}}\right)$ and density $\left(n_{e}\right)$ measured by the Langmuir probes and the brightness of the CD spectrum. From a value of 0.02 molecules per incident ion (ion flux of $6 * 10^{18} \mathrm{D}^{+} \mathrm{cm}^{-2} \mathrm{~s}^{-1}, \mathrm{~T}_{\mathrm{e}}=20 \mathrm{eV},\left\langle\mathrm{n}_{\mathrm{e}}\right\rangle=$ $5 * 10^{18} \mathrm{~m}^{-3}, \mathrm{SX} / \mathrm{B}$ for $\mathrm{CD}_{4}$ from $\mathrm{CD}(4310 \AA)$ of 110 dissociation processes per photon [6]) a brightness (and thus a calibration factor) was determined.

The reciprocating Langmuir probe referred to above was located $60^{\circ}$ toroidally and $90^{\circ}$ poloidally away from the limiter. $\mathrm{T}_{e}$ and $\mathrm{n}_{\mathrm{e}}$ just inside the last closed flux surface (LCFS) were

$\S$ Supported by a fellowship from the Oak Ridge Institute of Science and Education. 
measured by Thomson scattering. The surface temperature of the limiter was determined from black body radiation measured in the visible. The error bars for these measurements are $+/-20 \%$. Z $\mathrm{Z}_{\text {eff }}$ was determined from continuum bremsstrahlung measurements in the visible.

Two plasma conditions were studied; both were deuterium, ohmic plasmas. The first condition will be referred to as Series A for which the toroidal magnetic field was $3.8 \mathrm{~T}$, the minor radius $0.72 \mathrm{~m}$, the major radius $2.40 \mathrm{~m}$, the toroidal plasma current $1.54 \mathrm{MA}$, the safety factor 3.0 and the volume averaged electron density $3.9 * 10^{19} \mathrm{~m}^{-3}$. For Series $B$ these parameters were $3.80 \mathrm{~T}, 0.76 \mathrm{~m}, 2.36 \mathrm{~m}, 1.69 \mathrm{MA}, 3.1$ and $3.5 * 10^{19} \mathrm{~m}^{-3}$, respectively. Identical shots were repeated for each series to allow data for different wavelengths to be taken for the same optical view. Leading edge (located $1.5 \mathrm{~cm}$ radially away from the LCFS) data was taken for Series A parameters and data from near the tangency point (a few mm from the LCFS) was taken for Series B. The limiter was made from a large block of Carbon Lorraine graphite (5890 PT).

3. Experimental Results and Discussion. During earlier experiments an image of the C II emission from the entire limiter was measured with an interference filtered, CCD camera and the visible endoscope. From the 3D Monte-Carlo modelling (BBQ) of this data, it was determined that chemical sputtering was a significant source of carbon for the leading edge as well as possibly at the tangency point of the limiter [4]. Hence a search for direct evidence of chemical sputtering by-products $\left(\mathrm{C}_{2}\right.$ and $\mathrm{CD}$ molecular bands) was undertaken.

CD molecular bands were observed on both the leading edge (Fig. 1) and tangency point of the limiter for the plasma parameters of Series A and B. However, $C_{2}$ molecular bands were not identified in either location. In Fig. $2 a$ and $2 b$ the brightness of the $C D$ molecular band, integrated over a $15 \AA$ region starting at the $\sim 4310 \AA$ band head, is shown as a function of time for the leading edge region (Series A) and the tangency point region (Series B), respectively.

The limiter surface temperature, for the same region as the CD measurements, is also shown as a function of time. This surface temperature was determined from the black body radiation (measured at $\sim 6550 \AA$ for Fig. $2 \mathrm{a}$ and $\sim 5140 \AA$ for Fig. $2 \mathrm{~b}$ ). Since the black body radiation is too weak to determine the temperature below $\sim 1200^{\circ} \mathrm{C}$, the pre-shot temperature (measured by thermocouple gauges within the limiter) was related to the temperature determined from the black body radiation by the semi-infinite, one dimensional surface temperature scaling law, which states that the surface temperature varies as the square root of time. From experiments in which IR camera data is compared to this scaling law, it was determined that the surface temperature is somewhat over-estimated by this scaling law at the beginning of the shot; this over-estimation was corrected for. The temperatures measured from the black body radiation are consistent with IR camera measurements for similar plasmas.

The plasma was moved onto the limiter at $t=1.6 \mathrm{~s}$. From this time on, the plasma shape remained constant but the plasma current and density continued increasing until $t=3.5 \mathrm{~s}$, thus complicating the calculation for the maximum data points in Fig. $2 \mathrm{a}$ (maximum point $\mathrm{T}_{\mathrm{e}}=$ $20 \mathrm{eV}$, remaining points $\left.\mathrm{T}_{\mathrm{e}}=30 \mathrm{eV}\right)$ and Fig. $2 \mathrm{~b}(60 \mathrm{eV}$ and $80 \mathrm{eV}$, respectively)

It is shown in Fig. $2 a$ and $2 b$ that the production of methane was significantly reduced for temperature above $1100^{\circ} \mathrm{C}$ and negligible for temperatures above $1300^{\circ} \mathrm{C}$. Respective temperature ranges of $\sim 350^{\circ} \mathrm{C}$ to $\sim 700^{\circ} \mathrm{C}$ and $470^{\circ} \mathrm{C}$ and $770^{\circ} \mathrm{C}$ corresponded to the maximum methane flux for the two regions of the limiter. This is consistent with laboratory measurements [6], in which a surface temperature of around $550^{\circ} \mathrm{C}$ corresponded to the maximum methane yield on both the leading edge and tangency point.

In Fig. $3 \mathrm{a}$ and $\mathrm{3b}$ the molecular flux (SX/B of 110 diss./photon for highest point and 120 diss./photon for the remaining points [7]) and the $\mathrm{C}^{+}$particle flux $\left(\mathrm{T}_{\mathrm{e}}=30 \mathrm{eV}, \mathrm{SX} / \mathrm{B}=60\right.$ 
ioniz./photon [8]) were calculated from Fig $2 \mathrm{a}$ and $2 \mathrm{~b}$. A $300 \%$ decrease in the methane influx corresponds to a $10 \%$ decrease in the influx of single ionized carbon. This indicates that methane has a slight or negligible influence in the $\mathrm{C}^{+}$flux. Near the end of the shot the $\mathrm{C}^{+}$ signal increases significantly, this is attributed to RES since the only parameter simultaneously changing with the $\mathrm{C}^{+}$signal is the surface temperature. Variation in the $\mathrm{C}^{+}$signal from chemical sputtering and RES did not correspond to variation in $Z_{\text {eff. Traditionally, carbon is the }}$ only significant impurity in these plasmas. This lack of impact on the core impurity content is attributed to a low core penetration efficiency for both of these sputtering mechanisms.

4. Impurity transport calculations. The data have been modeled with the impurity code BBQ. The code incorporates a 3D Monte-Carlo description of both neutral and charged impurity transport in Tore Supra geometry. Impurity generation processes related to physical and chemical sputtering are included. Given the limiter temperature distribution and the incident $\mathrm{D}^{+}$flux parameters, BBQ calculates the evolution of both physical $(C)$ and chemical (CD4) sputter products. The code calculates spatial distributions of $\mathrm{CII}$ and $\mathrm{CIII}$ brightness. The physical sputter products are emitted with a Thompson energy distribution, with energies as high as $5-10 \mathrm{eV}$; the chemical products are emitted at the wall temperature $(0.1 \mathrm{eV})$ as $\mathrm{CD} 4$, which then experiences a break-up chain.

The measurements focus on the vicinity of the limiter. It is of importance to know what effect these processes have on core impurity accumulation. BBQ comparison allows us to see what the sensitivities are. Result shows (1) high penetration efficiency for physical, low for chemical, so physical dominates the core accumulation (2) a very strong dependence on basic surface data, with important (but somewhat less) dependence on uncertainties in SOL perpendicular transport.

5. Conclusion. A quantitative study of the role of temperature dependent sputtering mechanisms on the outboard limiter in Tore Supra was performed. The methane flux proved to be significantly reduced above surface temperatures of $1100^{\circ} \mathrm{C}$ and negligible above $1300^{\circ} \mathrm{C}$. The peak in the methane yield as a function of surface temperature is consistent with lab results. It was determined that chemical sputtering (early in the shot) had a small, to negligible, impact on the $\mathrm{C}^{+}$flux; while RES (late in the shot) had a strong impact on the $\mathrm{C}^{+}$flux. However, from the $\mathrm{Z}_{\text {eff }}$ measurements, it was concluded that neither process contributed to the core carbon content.

6. References.

[1] Shimizu, K., N. Hosogane, and T. Takizuka. IAEA Conference. 1994. Seville, Spain:

[2] Horton, L.D. and T.J. Team. IAEA Conference. 1994. Seville, Spain:

[3] Kallenbach, A., et al., Nuclear Fusion, 1994. 34(12): p. 1557-1565.

[4] Klepper, C.C., et al., J.Nucl. Mater., 1995. .

[5] Tobin, S.J. P. Monier-Garbet, J.T. Hogan et al. 1994. Monpelier, France: EPS.

[6] Roth, J., E. Vietzke, and A.A. Haasz, Atomic and Plasma - Material Interaction Data for Fusion, 1991. 1: p. 63-78.

[7] Poschenrieder, W., K. Behringer, J. of Nuclear Materials, 1995. : p. 36-49.

[8] Isler, R.C. private communication

7. Acknowledgment. We would like to thank the Tore Supra team, M. Chatelier, H. Garcin, J.H. Harris, K. Mony and P. Mioduszewski for their valued assistance; as well as, extend particular thanks to V. Philipps (TEXTOR).

\section{DISCLAIMER}

\footnotetext{
This report was prepared as an account of work sponsored by an agency of the United States Government. Neither the United States Government nor any agency thereof, nor any of their employees, makes any warranty, express or implied, or assumes any legal liability or responsibility for the accuracy, completeness, or usefulness of any information, apparatus, product, or process disclosed, or represents that its use would not infringe privately owned rights. Reference herein to any specific commercial product, process, or service by trade name, trademark, manufacturer, or otherwise does not necessarily constitute or imply its endorsement, recommendation, or favoring by the United States Government or any agency thereof. The views and opinions of authors expressed herein do not necessarily state or reflect those of the United States Government or any agency thereof.
} 


\section{Figures.}

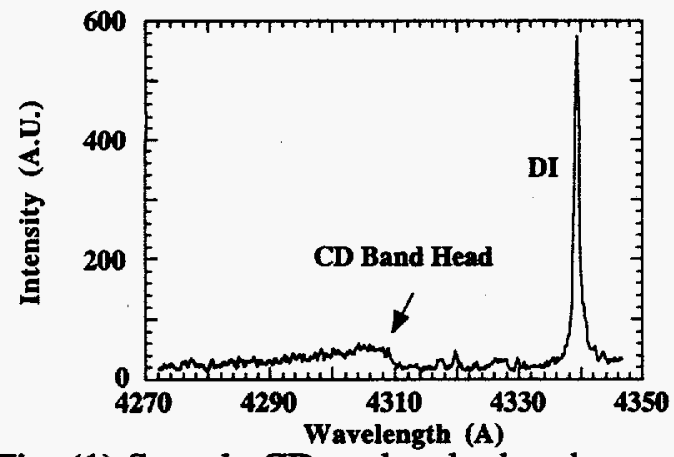

Fig. (1) Sample CD molecular band spectra

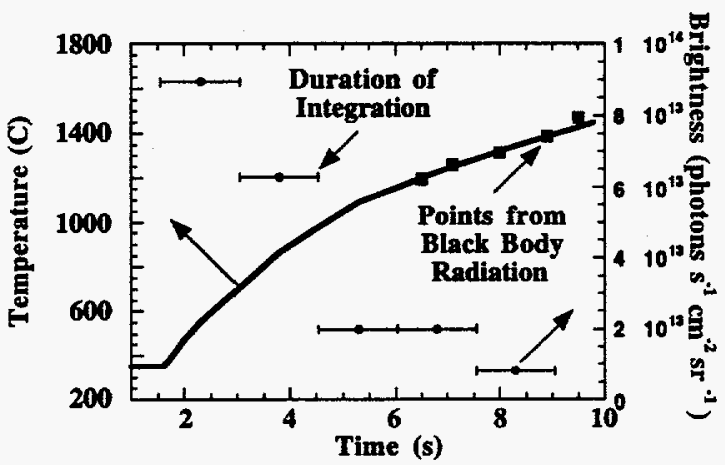

Fig. (2a) $C D$ brightness and surface temperature vs. time measured from the leading edge

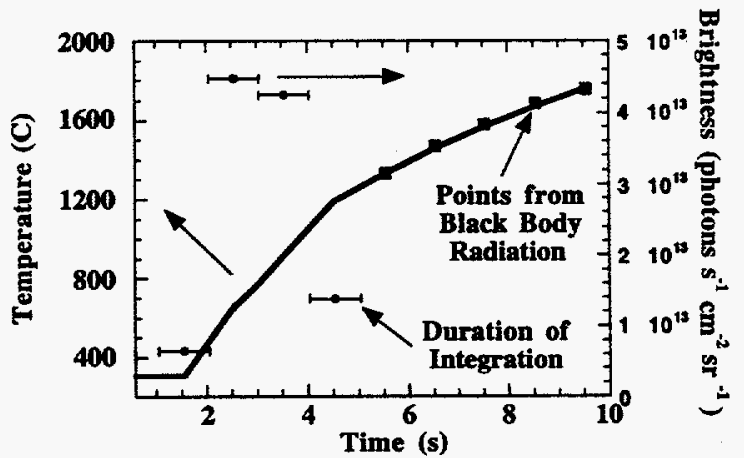

Fig (2b) CD brightness and surface temperature vs. time measured from the central tangency point. 


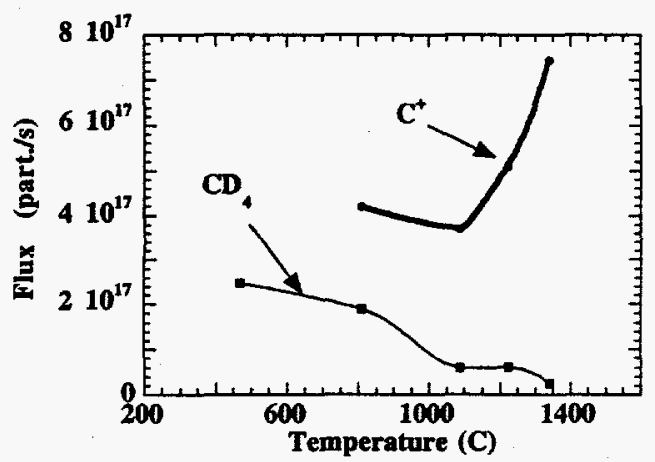

Fig. (3a) $\mathrm{C}^{+}$and $\mathrm{CD}_{4}$ flux vs. time measured from the leading edge .

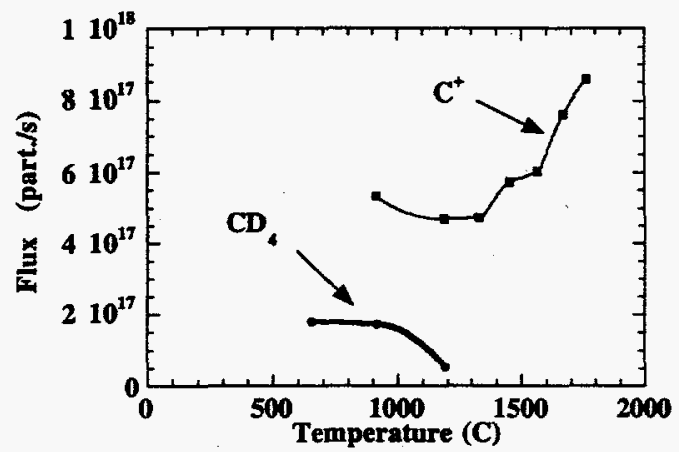

Fig. (3b) $\mathrm{C}^{+}$and $\mathrm{CD}_{4}$ flux vs. time measured from the central tangency point. 


\section{DISCLAMMER}

Portions of this document may be illegible in electronic image products. Images are produced from the best available original document. 